\title{
Good in theory, bad in practice: Practitioners' perspectives on the Early Years Pupil
}

Premium in England

Dr Zeta Brown

University of Wolverhampton, Gorway Road, Walsall, West Midlands, WS1 3EZ.

zeta.brown@wlv.ac.uk

Dr Zeta Brown is a Reader in Education for Social Justice at the University of

Wolverhampton. She is leader of the Children, young people and families' research cluster for the Centre for Developmental and Applied Research in Education. She is an executive member and currently Chair of the British Education Studies Association. Zeta's research predominately focuses on agendas and policies in the early years and primary education. 


\begin{abstract}
The paper investigates practitioners' perspectives on the Early Years Pupil Premium (EYPP) in England. The paper considers what practitioners in one Local Authority (LA) think now that the funding has passed its infancy. Specifically, does EYPP funding help 'close the gap' for disadvantaged 3-4 year olds?

Q-methodology was used to identify practitioners' shared perspectives and gather quantifiable data from highly subjective viewpoints. In total, the study investigated 19 practitioners' perspectives; all were owners or managers in 19 different settings across one LA.
\end{abstract}

The findings show that practitioners are experiencing administration and eligibility issues that hinder the effectiveness of the funding for disadvantaged children. The paper includes suggestions for improvements that include extending the eligibility criteria and providing more autonomy to practitioners to apply on behalf of children in their care. It concludes that EYPP funding is currently not working effectively for all of the participants in this study.

Keywords: Early Years, Pupil Premium, education, practitioners and funding 
Despite decades of research and debate, the issue of unequal outcomes continues to be a concern in educational systems worldwide.

(Bradbury, 2011, p.655)

\section{Early childhood policy: tackling inequality}

In England, successive governments have committed to reducing inequality between disadvantaged children and their peers:

...an array of policies have been developed with the single or dual aims of supporting disadvantaged children to catch up with their more affluent peers through access to good quality early education, and supporting poor families to work in order to reduce child poverty.

Mathers and Smees (2014, p.11)

Policies in England include free early education provision and the Early Years Pupil Premium. In order to reduce inequality and support school readiness, early years provision has, incrementally, become free for various age ranges in the last two decades. In 1996 the Conservative government announced free provision for 4 year olds. By 2005, 3-4 year olds were entitled to 15 hours free provision during school term times, a change introduced by the Labour government (Lloyd, 2015). This was honoured and extended by the Coalition and subsequent governments. In 2013, 2 year olds from low income families became eligible for free provision and in 2016, the Conservative government doubled the free provision awarded to 3-4 year olds for working parents (Gov.uk, 2018a). From 2016, all 3-4 year olds are entitled to free full-time early years provision.

\section{The Early Years Pupil Premium (EYPP)}

The Early Years Pupil Premium (EYPP) was also introduced in 2015 and targeted 3-4 year olds. The funding seeks to provide early intervention in closing the gap for disadvantaged children through high quality early childhood education (Early Education, 2018a). The government initiative provides eligible children with additional funds to support their education (Gov.uk, 2018b). The funding is $£ 302.10$ per annum (53p per hour for each child) 
and is focused specifically on children who are seen as disadvantaged. In this context that means children from low income families and looked-after children (LAC), including children who have been in Local Authority (LA) care for 1 day or more, those who have left care under special guardianship or residential orders and children adopted in England and Wales. The focus of EYPP is to provide support for 'closing the gap' alongside established strategies to help children and their families.

\section{Similarities and differences between EYPP and the Pupil Premium}

The EYPP was intended to bridge the gap for eligible 3-4 year olds until they are able to claim the Pupil Premium. The Pupil Premium (established since 2010) similarly provides funding for disadvantaged children and aims to raise their educational achievement (West, 2015). In 2018 , the rates are $£ 1300$ for primary children and $£ 935$ for secondary aged pupils. LAC are eligible for a higher amount of $£ 2300$ per annum (Gov.uk; 2018d). In 2015, press releases focused on how the EYPP would further support the educational attainment of disadvantaged children. Sam Gyimah, Childcare Minister at this time said:

I'm delighted we are helping the most disadvantaged children access high-quality early education, giving them the best possible start in life. The early years pupil premium gives money to providers so they can make sure eligible children have the best possible outcomes when they start school and beyond. The early years count and it will be life-changing for many of these children. I would encourage any parent who meets the criteria to let a local provider know, so that their child can get the right support at the right time.

(Gov.uk, 2018c)

There are, however, clear disparities in the amount of funding from the EYPP for children aged 3-4 years and the amount they will receive when they are entitled to the Pupil Premium. One study conducted by Mathers and colleagues $(2016$, p.69) questioned how much the EYPP can close the gap for disadvantaged children given its limited resource. It found that participants did not consider the amount sufficient for LAC and called for it to match the pupil premium '... to meet the potential significant needs of LAC.' This study wasn't specifically focused on EYPP funding but included it in its practice recommendations for LAC.

\section{Existing research on the EYPP: the eligibility criteria.}


Since 2015 there has been limited literature that examines the Early Years Pupil Premium. Most of the literature consists of official documents designed to support practitioners and settings to use the funding effectively (Early Education, 2018b). To date, there appears to be only one publicly available project that has explored issues around EYPP funding. Early Education carried out a project in 2015-16 that was entitled, 'Learning Together About Learning' (LTAL). The project was funded by the Department for Education and its findings supported indications that the EYPP funding did make a difference to children's outcomes.

However, this was not the claimed aim of the project: its aims were to support the effective introduction of EYPP funding in the first year of its implementation (Early Education, 2018a). The project found that there was some difficulty in identifying eligible children. Some LAs identified these children but others did not. The funding was paid along with the Nursery Education Grant and left some practitioners trying to work out how much they had received and for which children, or even if they had received funding at all.

The EYPP eligibility criteria, like those for the Pupil Premium, include children experiencing a broad range of home environments. The criteria are based on whether they are looked-after or from low income families rather than being based on individual need. This means that children can be eligible for this funding who have no area of developmental delay. The Early Education (2018b, p.4) project suggested that:

the purpose of EYPP funding is to ensure those children who are inexperienced make accelerated progress to close the gap between their progress and that of their less disadvantaged peers. It could also be used to ensure those EYPP children who are currently where they are expected to be in terms of attainment and progress, are enabled to be more experienced in some areas of learning.

It also recommended that practitioners compare the progress of EYPP children with nonEYPP children to make sure that all children who have been identified as being 'inexperienced' or 'not meeting age related expectations' make progress, presumably to ensure that children who are not eligible for EYPP continue to have their developmental needs met (Early Education, 2018b, p.8).

The application process. The Early Education report also noted 'teething problems' in the administration processes. There were delays accessing the funding and lower numbers than expected claimed successfully in the first year. Some settings reported that they felt 'the 
effort to claim was too great.' Settings received funding at different times in the term. One practitioner said, 'It takes more than half a term to get paid the EYPP, we are therefore only spending it in the second halves of a term.'

Local Authorities were tasked with devising their own application processes. This meant that some used separate forms, some expanded the Nursery Education Grant funding form and some liaised with departments responsible for benefits claims to identify eligible families and didn't require a separate form. The last was only achieved in unitary authorities. Settings which used separate forms reported that parents were unwilling to fill in another form. Settings had differing strategies to encourage parents to apply. These included incentives to boost intake and supporting parents by filling in the form with them. Some participants reported that there was not enough time to 'chase' returns from all eligible families and this left them judging who was 'worth' chasing. Practitioners reported wanting a more universal method for claiming the funds where no additional form was necessary. The Early Education report recommended that practitioners provide parents with information on the advantages of applying for EYPP. They also recommended providing the same information to all parents to reduce the stigma associated with applying and to maximize uptake (Early Education, 2018a).

The role of the parents, practitioners and Ofsted. The government retains centralized control of EYPP eligibility criteria and LAs are responsible for the application process. However, practitioners are left to decide how the funding will be used to support the needs of eligible children. The Early Education report noted that practitioners had more knowledge of EYPP funding if they were involved in the project's networks (Early Education, 2018a).

The breadth of ways the funding can be used is vast, including resources for an individual child's development, group resources that support more than one eligible child, parental support, staff training and professional development. Examples in the Early Education project included support materials covering topics such as toilet training, enrichment activities, such as a visit to a wildlife park, additional forest school provision, speech and language sessions for parents and a professional library to support staff to refine pedagogical thinking (Early Education, 2018a, p.8). Whilst practitioners are responsible for using the funding appropriately, Ofsted is responsible for deciding whether the funding is being spent wisely, with 'maximum impact.' Early Education stated, 
Even if you don't claim the funding, Ofsted will expect you to demonstrate how you are providing additional support for eligible children - so it makes little sense not to claim the funding that would support that activity

adding:

It's also likely that if EYPP is claimed widely and used effectively, the sector will be better able to argue the case for increasing it to a similar level to schools' pupil premium in future. Whereas, if the sector doesn't use it, it may lose it.

(Early Education, 2018b, p.2)

In 2018, the EYPP is still available with the same application process, eligibility criteria and rates as in 2015. It is vital to find out what practitioners think about this funding now that it is past its infancy. Does EYPP funding help 'close the gap' for disadvantaged 3-4 year olds?

\section{The study's methodological design}

The present study had two main objectives. First, it sought to investigate the views of practitioners on their general use of EYPP funding for disadvantaged children. Second, it aimed to investigate practitioners' decisions on how this funding is used specifically for LAC. This paper focuses on the study's first objective. The research questions associated to this objective were as follows:

- What are practitioners' perspectives on the EYPP funding?

- Is EYPP effective according to practitioners' perspectives and does it 'close the gap' for disadvantaged children?

The study sought to identify shared perspectives across the participants on this funding, including whether they shared similar views on the EYPP's application and eligibility criteria.

The intepretivist focus of the study was on the participants' positions, acknowledging that these positions and one's actions can alter over time and can be dependent on situational circumstances. Findings can then be compared and contrasted between different periods of time or between different places (Cohen et al., 2011). 
To identify shared perspectives, this study used Q-methodology. Q-methodology was deployed because it is a means of gathering quantifiable data from highly subjective viewpoints (Brown, 1997). Q-methodology investigates the complexity in different participant's positions on a given subject where differences of opinion are expected (Combes, et al., 2004). Q-methodology is a way of thinking about research that focuses on providing subjectivity to participants. This approach to research enables an exploration of shared meaning through consideration of the social context in which participants find themselves (Kitzinger, 1999). Q-methodology involves participants sorting a set of statements onto a distribution grid, shaped as a reversed pyramid. Participants sort these cards based on whether they agree or disagree with each statement. The distribution went from -4 (strongly disagree) to 4 (strongly agree). As such, participants are comparing and contrasting the statements - there is no right or wrong response in the card sort (Brown, 1991/1992).

Q is well known for its facility to generate large amounts of quantitative and qualitative material from very small numbers of participants (Watts and Stenner, 2005). Data collection occurred on one day during the LA's Private, Voluntary and Independent (PVI) Sector Senior Leadership update meeting. Attendees (who are owners and managers of settings) were asked if they wanted to take part in the project and provided time during this update to be part of the research.

In total, 20 practitioners sorted 34 statements at the same time during the update. These statements covered differing perspectives on EYPP funding. They were derived from discussion with a focus group drawn from the LA's 'good to outstanding' group. The generated statements were taken to the same group for respondent validation before being used in the project's main data collection activity. Example statements include: the funding is essential to support children's development; all children from low income families need this funding, and; some LAC miss out because the adoptive parents don't declare their status (please see Appendix 1 for the full list of statements and factor arrays). There were approximately 50 attendees at the update (all owner/managers); 24 decided to take part in the study and 20 successfully completed the card sort and were included in the analysis.

To enhance the qualitative data at card sort, participants were asked to describe on a report sheet why they had placed statements in the most extreme distribution columns. These 
findings are included as direct quotes in the factor interpretations. Q data is analysed collectively to produce consensus viewpoints, or factors, which have statistical significance. The distribution data was analysed using PQ method, which is a computerised method of inputting data and producing factors (Eden, Donaldson and Walker, 2005). There are differing ways that the data can be analysed; however, in this study centroid analysis was used to extract factors for varimax rotation. The study retained factors that had an eigenvalue (strength of that factor in relation to others) of 1.00 or higher.

In total, three factors were kept for interpretive analysis and are detailed in this paper. The factors in this study represent 19 of the 20 practitioners included in the analysis. This is because one of the participant's perspectives did not load on any one factor. Therefore, the sample represents 19 perspectives from owners/managers of 19 settings in one LA.

\section{Validity and ethical considerations}

Cohen and colleagues (2011) believe that qualitative researchers should describe validity in terms of how far their research is able to detail participants' positions. Considering qualitative research in its entirety, validity is improved in this study in three different ways with the use of a pilot study; peer debriefing (when generating the Q statements) and respondent validation (by going back to the focus group participants to approve the $\mathrm{Q}$ statements).

The British Education Research Association's (BERA) (2011) ethical guidelines indicate that researchers need to disclose all relevant information regarding their research, prior to it being conducted. This study ensured that participants signed a written consent form that detailed all relevant research information, prior to their participation in the research. Data collection began with a short presentation about the project to all attendees at the PVI update.

Attendees were made aware that participation in the study was voluntary and that they could choose to take a break instead of participating in the data collection. There was a mixed response, with around half the group deciding to participate. This showed that participants felt able to decide not to participate in the study. It was vital in this study, because the data is from one LA, that confidentiality was ensured for the LA, settings and participants. 
Participants' identities are not disclosed and instead only general demographic information is mentioned.

\section{Findings}

Factor One: 'There are limitations to the EYPP funding; the application process has got to change.'

The amount of variance accounted for is $35 \%$ and its eigenvalue is 6.9225 , which is over six times the value needed to be a significant factor. In total, eight practitioners held these commonalities in their positions. Table 1 represents the practitioners' demographic information.

[Table 1]

These practitioners held strong perspectives on the EYPP. Their position was, interestingly, not influenced by Government objectives (12 statement number; -3 column number) but they focused on highlighting the limitations of the funding because of its application process. These practitioners do not think the funding could be better spent elsewhere $(15 ;-2)$. Participant seven said 'I feel the concept in theory is great' and participant fourteen added, 'I do feel there is a need for this but it is how it is allocated and claimed and late payments that is problematic.' They also believe that more funding should be allocated per child $(8 ; 2)$.

They do not believe that the funding at present 'closes the gap' for LAC $(21 ;-3)$ or children from low income families $(22 ;-2)$. Participant fourteen said, 'it is difficult to spend money to 'bridge a gap' that isn't there.' Participant eight added 'it's too blunt a tool. It's not based on the child.' They also do not believe that all LAC need this funding (5; -3). Participant thirteen declared 'not all LAC need additional support and often the government dictate on what 'they' think best rather than giving choice to those who know best.' They strongly disagree that all children from low income families need this funding $(14 ;-4)$. Participant four said 'some low income families are single parents in our area [but also have] well 
rounded children without weak areas.' Participant fourteen added, 'not all children who can claim need the money to improve their outcomes.' Instead they choose to use the funding for group activities that benefit more than one child $(6 ; 2)$.

These practitioners placed many of the statements detailing the funding application process in the most extreme columns of the distribution grid. These practitioners state that it is not easy to access the funding $(9 ;-4)$. Participant seven said 'the process of identifying, application and allocation of funding is laborious.' They believe that it is a struggle to get parents to complete the online form $(27 ; 4)$. This was specifically mentioned by several of the participants. They said, 'it is a struggle to get parents to apply themselves, we have to support them' (participant four) and 'trying to get parents to apply and making the judgement about identifying which families are eligible is difficult' (participant seven). Participant nineteen added that it is '... difficult for parents to understand so they don't bother to apply, especially after they have already filled in the numerous forms etc required to register their child at nursery.' They would prefer instead to apply for the funding on behalf of children in their care $(28 ; 3)$.

This group strongly stated that they get the funding too late in the academic year $(7 ; 4)$ and they have children who are eligible for the funding but have not received it $(29 ; 2)$. This was specifically mentioned by several of this factor's participants. They said 'we get the funding too late, sometimes the child has moved to reception' (participant four). 'We are out of pocket for terms for interventions, equipment, staffing' (participant seven). Participant thirteen reiterated that the '...practicalities of getting funding [are] limited which puts strains on early years to resource themselves.' Participant eight concluded that it is 'too hard to claim, comes in too late... Not enough money to make a difference. It's a government soundbite not communicated well enough to families. Some families find it embarrassing.'

Interestingly, they were indifferent about changing the eligibility criteria for this funding (32; 0). However, they do state that they have children who are not eligible for this funding but would benefit from it $(30 ; 3)$. They also state that children with Special Educational Needs and Disabilities should be entitled to this funding $(16 ; 2)$. They do not believe that parents/carers are involved in how they use the funding $(2 ;-2)$. Participant seven revealed that 'parents/carers are informed about spending, which targets it will address but they don't decide how it's spent.' 
They would like more autonomy themselves to allocate the funding to children who really need it $(4 ; 3)$. Participant thirteen said 'if we could choose children who need it and access funding immediately I feel this would benefit the child and setting better.' Similarly, participant fifteen stated, 'we work with the children and know the ones who need the funding.'

\section{Factor two: 'The EYPP funding is beneficial, but it is not accessible to all who need it'}

The amount of variance accounted for is $6 \%$ and its eigenvalue is 1.2481 , which is comfortably over the amount needed to be a significant factor. In total, seven participants held these commonalities in their positions (see Table 2). These participants worked mostly in nurseries; they are mostly managers at these settings and all had over 10 years' experience.

[Table 2]

In contrast to factor one, these participants believe the EYPP funding is essential to support children's development $(1 ; 2)$ and they generally stated that all funding in the early years is good funding $(19 ; 2)$. Participant twenty said, 'it is good for the children that need additional support.' Participant seventeen also stated, 'I think it is a very good idea but it is not always simple in practice.' They didn't believe the funding could be better spent elsewhere $(15 ;-3)$ and believe that Ofsted is interested in how they use the funding $(24 ; 2)$. Additionally, they did not believe that extra funding was needed per child $(8 ;-2)$.

It is important to state that these participants also declared that they had not been responsible for allocating this funding in their setting (26; -3). Participant two stated, 'never had a child granted EYPP funding. Asked parents to apply via email links...no EYPP granted...so far.' Similarly, participant three said, 'as of yet haven't had a child eligible for this funding.' This may be why they also state that their position is not influenced by general experience $(11 ;-2)$. They also placed statements about its use in the neutral columns of the distribution grid. For instance, they were indifferent about parents/carers being involved in how they use the funding $(2 ; 0)$, whether it is more difficult to decide how to use the funding for LAC $(20 ; 0)$ and whether they have autonomy to decide how best to use this funding $(13 ; 0)$.

As with factor one, these practitioners highlight difficulties in the application process. They state that parents are not aware of the funding $(25 ;-4)$ and it is a struggle to get parents to 
complete the online form $(27 ; 3)$. This was mentioned specifically by several participants. Participant six explains that 'parents don't always declare that they have an adopted child.' This was extended further by participant seventeen 'I find it a continuous battle to get parents to fill in the online form. I send out letters and talk to parents on the door. I even offer support and time to fill it in with parents.' Participant nine also added 'It is a huge struggle to get parents to agree to the funding sometimes as they can sometimes see it as a status/pride issue that they don't want to claim the funding.'

This group does not think the funding is easy to access $(9 ;-4)$ and would prefer to apply for the funding on behalf of children in their care $(28 ; 4)$. Interestingly, they did not state that the funding arrived too late in the academic year $(7 ; 0)$ and they did not think that children in their setting were eligible for the funding, without receiving it $(29 ;-1)$. These statements they chose to place in the middle columns of the distribution grid. This was particularly surprising as they did not strongly agree with the statement that referred to the need for eligibility changes $(32 ; 1)$. They strongly agreed that they had children who were not eligible for this funding, but would benefit from it $(30 ; 4)$. Participant five said that it needs '... to be more accessible to all children who need help.' Participant nine added, 'because we feel that we have children who would benefit - however they would miss out due to the criteria.'

They agreed that Children with SEND should be entitled to this funding (16;2). Participant seventeen explained, 'children with special need, need extra support which is not available at all times - pay for extra staff and resources.' They didn't strongly agree that all LAC $(5 ; 1)$ and all children from low income families $(14 ; 1)$ need this funding. They also do not believe that the funding 'closes the gap' for LAC $(21 ;-1)$ and children from low income families (22; -2). They do not always know how to use the funding for each child ( $3 ;-3)$. Participant nine explained 'I feel that EYPP is great when it is used effectively for a child but if a child doesn't have any areas of developmental delay it can be hard to identify where support is needed.'

The group agreed that they find it difficult to decide how to use the funding if the child has no developmental delay $(33 ; 3)$. They appear to not consider using the funding for group activities to benefit more than one child as this statement was placed in the neutral columns of the distribution grid $(6 ; 0)$. In comparison to factor one, they believe that the funding would be better used if they could allocate it to children whom they feel really need it $(4 ; 3)$. Participant six added '... if settings were able to apply on behalf of the family - this might 
help the process - speed it up' and participant seventeen said that she '...think(s) we need more control to access funding and know who has applied for funding.' Participant three declared, 'funding should be targeted to meet need rather than automatically being based on need/looked after status. We have many children who would benefit but don't meet the criteria.'

Factor three: 'The EYPP funding has application and eligibility issues, but it is essential funding. It can support "eligible” children's development and others in the setting'

The amount of variance accounted for is $7 \%$ and its eigenvalue is 1.3709 , which is over the value needed to be a significant factor. In total four practitioners held these commonalities in their positions. These participants mostly worked in nurseries and were managers, and those who supplied information on their careers had over 12 years' experience.

[Table 3]

In contrast to factor one and comparison to factor two these practitioners strongly believe that the funding is essential to support children's development $(1 ; 3)$. Participant twelve said, 'funding [is] essential for 1:1 support and small group work.' Participant sixteen added, 'the EYPP is very useful and allows practitioners to focus upon a child's next steps; funding provides PVI settings with the financial freedom to purchase resources otherwise out of remit.' They agree that all funding in the early years is good funding $(19 ; 2)$ and strongly state that the funding could not be better spent elsewhere $(15 ;-4)$.

Interestingly, they do not state where their position has originated from; instead these statements are in the more neutral areas of the distribution grid. For instance, they do not agree or disagree that their position is influenced by their general experience $(11 ; 0)$, by experience particularly with one child $(34 ; 0)$ or by Government objectives $(12 ;-1)$. They did however believe that the government gives clear guidance on how to use the funding $(18 ;-3)$. These participants therefore are well acquainted with the funding, but have not necessarily had direct experience with it. Participant eighteen's views were influenced by not experiencing EYPP funding in her setting. She said 'as we have not and do not receive funding currently, this has influenced my statements.' 
Interestingly, they do not agree that funding should only be used on resources or support inside the setting $(31 ;-2)$. They do not strongly agree that they have autonomy to decide how to best use it $(13 ; 1)$. They also disagree that parents and carers are involved in how they use the funding $(2 ;-3)$. Participant twelve stated, 'parents/carers would not always understand setting needs and cannot always identify what would help close the gap.' In contrast to factors one and two they do not agree that the funding would be better used if they could allocate it to children whom they feel really need it $(4 ;-1)$. They do not always know how they will use the funding for each child $(3 ;-1)$. However, they find no extra difficulty in allocating funding to LAC $(20 ;-3)$ or children who have no developmental delay $(33 ;-2)$.

Similarly to factor one they strongly agree that they get the funding too late in the academic year $(7 ; 4)$. Participant twelve said that funding is 'received too late in [the] term to plan interventions. Term 3- children have left [the] setting for school before EYPP [is] received.' Participant eighteen added, 'funding is not allocated in the timescale needed to influence the child/ren applied for.' They believe that it is a struggle to get parents to complete the online form $(27 ; 3)$ and they would prefer to apply for the funding on behalf of children in their care (28; 4). Participant eleven stated, 'parents do not want to apply online, they don't seem to understand how it will benefit their child or the setting.'. In contrast to factor one, they strongly disagree that they have children in their setting who are eligible for this funding, but have not received it $(29 ;-4)$.

This group agreed with the statement that specifically stated that the eligibility criteria need to change $(32 ; 2)$. Participant eighteen declared that the funding 'needs to be extended to all children with developmental delays and the eligibility needs to be revised.' They have children who are not eligible for this funding, but would benefit from it $(30 ; 2)$. They state that children with SEND should be entitled to this funding $(16 ; 2)$. They do not agree that all LAC $(5 ;-2)$ and mildly agree that all children from low income families $(14 ; 1)$ need this funding. They also held a weak agreement that the funding 'closes the gap' for LAC $(21 ; 1)$ and do not agree that the funding 'closes the gap' for children from low income families (22; $0)$. Importantly, they use the funding for group activities that benefit more than one child (6; 3). Participant sixteen stated, "with or without the EYPP, I feel I would know what interventions or support was needed for the children in my care.'

\section{Discussion}

The EYPP funding is good in theory... 
Sam Gyimah's comments in 2015 introduced EYPP funding as 'life-changing' for eligible children (Gov.uk, 2018c). However, these participants' perspectives on its use differed on whether the EYPP funding is essential to support children's development. Factors two and three did welcome the funding and agreed it was essential to support children's development. However, they equally agreed that generally all funding in early years is good funding. On the contrary, factor one did not welcome the funding and held a weak agreement that all funding is good funding.

When specifically referring to LAC and children from low income families, none of the factors strongly believed that the funding 'closes the gap'. Table 4 below shows the findings for these specific statements.

[Table 4]

These findings directly counter the objectives of the EYPP funding (Early Education, 2018a; Gov.uk, 2018b). This does not mean that these participants didn't see value in providing funding for children who need it to rectify developmental delay. It is interesting to note that all factors stated that they have children in their setting that would benefit from the funding, but are not eligible for it (F1, 3 column number for each factor; F2, 4; F3, 2). Disagreements centred more on the application process and eligibility criteria. For factor one participants more funding also needs to be allocated per child $(8 ; 2)$, which is comparable with Mathers and colleagues (2016) results focused on LAC funding.

\section{But it's bad in practice...}

Participants presented a variety of perspectives on the struggles and barriers they face to access and effectively use EYPP funding. However, there were consistencies around the application process and eligibility criteria. Two or more factors agreed or disagreed with the statements below:

[Table 5] 
Many of these issues are comparable with barriers reported in the first years of the EYPP's implementation by Early Education (2018a). The report noted administrative issues, including delays in accessing funding and low numbers of successful claims as 'teething problems.' However, these issues are clearly continuing for participants in this study.

It is imperative to mention here that all three factors found difficulty in accessing funds. Factor one was the only factor to agree that they had children who were eligible for the funding, yet hadn't received it. The Early Education project (2018a) reported that practitioners held more positive perspectives when they received funding for more than one child in their setting. It can be inferred that participants in this study were likely to have more positive views if they received the amount of funding their children are entitled to. Factors one and three both stated that they use funding for group activities that benefit more than one child $(6 ; F 1,2 ; F 3,3)$. It is understandable that little may be achievable with just over $£ 300$ for one child. However, multiple claims for one setting have the potential to benefit more than the children eligible for the funds if they are used for appropriate group activities.

Finally, none of the factors strongly agreed that Ofsted is interested in how they use the funding. Only factor two placed this statement in the agreed column of the distribution grid $(24 ; \mathrm{F} 1,1 ; \mathrm{F} 2,2 ; \mathrm{F} 3,0)$. This is despite some of these settings recently being Ofsted inspected. This inevitably brings forth questions on whether Ofsted (in this LA) is concerned about whether the funding is being claimed, how it's being spent and whether it's 'closing the gap' for disadvantaged children.

\section{Concluding comments:}

The EYPP funding is clearly not working for participants in this study. There were potential improvements proposed in the findings that include:

- A higher EYPP rate

- Extending the eligibility criteria

- Timely provision of funds

- Providing more autonomy to practitioners to apply for the funding

- Enabling practitioners to apply for any child who needs additional funding to support their development. 
Perhaps the most significant issue to address is changing the application process so that settings are awarded the correct funds for their eligible children. If this can be achieved then the fund can be spent on resources, support and/or training that could support all children in the setting.

The use of Q methodology has shown that these practitioners, who all have leadership roles, have a range of viewpoints and value sets. They did not produce one factor that represented all of their perspectives on this funding. It is important that the government takes into account the range of viewpoints on the use of EYPP funding.

This project is not without its limitations. An advantage of the study is that it includes 19 differing settings in one LA. However, that is not a sufficient number of settings to allow generalization of these findings across all in England. This was not the purpose of this particular study, though issues raised are likely to be relatable to the wider field. These issues need to be explored on a national scale.

In conclusion, it is important to return to the project's research questions. Practitioners' perspectives were mostly focused on struggles and barriers that prevented them accessing the funding and using it for those who need and would benefit from it. For these participants, the EYPP funding is currently not effective and changes, many consistent with barriers reported in the Early Education (2018a) Report, need to be implemented in order to maximize the impact of this funding.

\section{References:}

BERA (2011) 'Ethical Guidelines for Educational Research.'

http://www.bera.ac.uk/files/2011/08/BERA-Ethical-Guidelines-2011.pdf. (Accessed July $27^{\text {th }}$ 2018).

Bradbury, A. (2011) Rethinking assessment and inequality: the production of disparities in attainment in early years education. Journal of Education Policy. 26(5), pp.655-676.

Brown, S. (1991/1992) 'A Q Methodological tutorial.' Accessed September $20^{\text {th }} 2009$. http://facstaff.uww.edu/cottlec/QArchive/Primer1.html

Brown, S. (1993) A Primer on Q Methodology. Operant Subjectivity. 16(3/4), pp.91-138. 
Brown, S. (1997) The history and principles of $Q$ methodology in psychology and the social sciences. Kent, OH: Kent State University.

Cohen, L., Manion, L., Morrison, K. and Bell, R. (2011) Research Methods in Education. ( $^{\text {th }}$ ed.). London: Routledge.

Combes, H., Hardy, G. and Buchan, L. (2004) 'Using Q-methodology to Involve People with Intellectual Disability in Evaluating Person-Centred Planning.' Journal of Applied Research in Intellectual Disabilities, 17(-), pp.149-159.

Early Education (2018a) EYPP project: Learning together about learning. [online]. https://www.earlyeducation.org.uk/sites/default/files/EYPP\%20final\%20report\%20May\%202016.pdf. [accessed July $25^{\text {th }} 2018$ ].

Early Education. (2018b) Practical tips on allocating Early Years Pupil Premium funding. Guidance from the Learning Together About Learning project, funded by the Department for Education. [online]. https://www.early-education.org.uk/sites/default/files/EarlyEd_Tip_EYPPs\%20ONLINE\%20small_0.pdf. [accessed July $25^{\text {th }} 2018$ ].

Eden, S., Donaldson, A. and Walker, G. (2005) 'Structuring subjectivities? Using Q methodology in human geography.' Area. 37(4), pp.413-422.

Gov.uk. (2018a) Thousands of parents benefit from 30 hours free childcare early. [online]. https://www.gov.uk/government/news/thousands-of-parents-benefit-from-30-hours-freechildcare-early. [Accessed July $26^{\text {th }} 2018$ ].

Gov.uk. (2018b) Early Years Pupil Premium: guide for local authorities. [online]. https://www.gov.uk/guidance/early-years-pupil-premium-guide-for-local-authorities. [Accessed June 10 $0^{\text {th }}$ 2018].

Gov.uk. (2018c) Extra funding to prepare for the early years pupil premium. [online]. https://www.gov.uk/government/news/extra-funding-to-prepare-for-the-early-years-pupilpremium. [Accessed June 10 ${ }^{\text {th }} 2018$ ].

Gov.uk. (2018d) Pupil Premium: funding and accountability for schools. [online]. https://www.gov.uk/guidance/pupil-premium-information-for-schools-and-alternativeprovision-settings. [Accessed July $26^{\text {th }} 2018$ ].

Lloyd, E. (2015) Early childhood education and care policy in England under the Coalition Government. London Review of Education. 13(2), pp.144-156. 
Mathers, S., Hardy, G., Clancy, C., Dixon, J. and Harding, C. (2016) Starting out right: early education and looked after children. [online]. http://www.education.ox.ac.uk/wordpress/wpcontent/uploads/2010/07/Starting-out-right_LAC-and-early-education_Dec-2016-1.pdf. [Accessed July 25 $5^{\text {th }} 2018$ ].

Mathers, S. and Smees, R. (2014) Quality and Inequality. Do three- and four-year-olds in deprived areas experience lower quality early years provision? Nuffield Foundation. [online].

https://www.nuffieldfoundation.org/sites/default/files/files/Quality_inequality_childcare_mat hers_29_05_14.pdf. [Accessed July $20^{\text {th }} 2018$ ].

Watts, S. and Stenner, P. (2005) Doing Q methodology: theory, method and interpretation. Qualitative Research in Psychology. 2(-), pp.67-91.

West, A. (2015) Education policy and governance in England under the Coalition Government (2010-2015): Academies, the pupil premium, and free early education. London Review of Education. 13(2), pp.21-36.

\section{Appendix 1}




\begin{tabular}{|c|c|c|c|c|c|}
\hline No. & Statement & No. & 1 & 2 & 3 \\
\hline 1 & $\begin{array}{l}\text { The funding is essential to support children's } \\
\text { development }\end{array}$ & 1 & -1 & 2 & 3 \\
\hline 2 & $\begin{array}{l}\text { Parents/carers are involved in how we use the } \\
\text { funding }\end{array}$ & 2 & -2 & 0 & -3 \\
\hline 3 & $\begin{array}{l}\text { I always know how I will use the funding for each } \\
\text { child }\end{array}$ & 3 & 0 & -3 & -1 \\
\hline 4 & $\begin{array}{l}\text { The funding would be better used if I could allocate } \\
\text { it to children whom I feel really need it }\end{array}$ & 4 & 3 & 3 & -1 \\
\hline 5 & All looked-after children need this funding & 5 & -3 & 1 & -2 \\
\hline 6 & $\begin{array}{l}\text { I use the funding for group activities to benefit more } \\
\text { than one child }\end{array}$ & 6 & 2 & 0 & 3 \\
\hline 7 & We get the funding too late in the academic year & 7 & 4 & 0 & 4 \\
\hline 8 & More funding needs to be allocated per child & 8 & 2 & -2 & 0 \\
\hline 9 & It is easy to access this funding & 9 & -4 & -4 & 0 \\
\hline 10 & $\begin{array}{l}\text { I do not know how the effects/benefits of this } \\
\text { funding are measured }\end{array}$ & 10 & -2 & -2 & -2 \\
\hline 11 & My position is influenced by my general experience & 11 & 0 & -2 & 0 \\
\hline 12 & My position is influenced by government objectives & 12 & -3 & -1 & -1 \\
\hline 13 & $\begin{array}{l}\text { I believe I have autonomy to decide how to best use } \\
\text { this funding }\end{array}$ & 13 & 1 & 0 & 1 \\
\hline 14 & $\begin{array}{l}\text { All children from low income families need this } \\
\text { funding }\end{array}$ & 14 & -4 & 1 & 1 \\
\hline 15 & Funding could be better spent elsewhere & 15 & -2 & -3 & -4 \\
\hline 16 & $\begin{array}{l}\text { Children with Special Educational Needs and } \\
\text { Disabilities should be entitled to this funding }\end{array}$ & 16 & 2 & 2 & 2 \\
\hline 17 & $\begin{array}{l}\text { Some LAC miss out because the adoptive parents } \\
\text { don't declare their status }\end{array}$ & 17 & 0 & -1 & -1 \\
\hline 18 & $\begin{array}{l}\text { The government need to give clearer guidance on } \\
\text { how this funding can be used }\end{array}$ & 18 & -1 & 1 & -3 \\
\hline 19 & All funding in early years is good funding & 19 & 1 & 2 & 2 \\
\hline 20 & $\begin{array}{l}\text { I think it is more difficult to decide how to use the } \\
\text { funding for looked-after children }\end{array}$ & 20 & -1 & 0 & -3 \\
\hline 21 & $\begin{array}{l}\text { This funding 'closes the gap' for looked-after } \\
\text { children }\end{array}$ & 21 & -3 & -1 & 1 \\
\hline 22 & $\begin{array}{l}\text { This funding 'closes the gap' for children from low } \\
\text { income families }\end{array}$ & 22 & -2 & -2 & 0 \\
\hline 23 & This funding supports inclusive practice & 23 & 1 & 1 & 1 \\
\hline 24 & Ofsted are interested in how we use this funding & 24 & 1 & 2 & 0 \\
\hline 25 & Parents are aware of the funding & 25 & -1 & -4 & -1 \\
\hline 26 & $\begin{array}{l}\text { I have been responsible for allocating this funding } \\
\text { for at least one child in my setting }\end{array}$ & 26 & 1 & -3 & 1 \\
\hline 27 & $\begin{array}{l}\text { It is a struggle to get parents to complete the online } \\
\text { form }\end{array}$ & 27 & 4 & 3 & 3 \\
\hline 28 & $\begin{array}{l}\text { I would prefer to apply for the funding on behalf of } \\
\text { children in my care }\end{array}$ & 28 & 3 & 4 & 4 \\
\hline 29 & $\begin{array}{l}\text { I have children in my setting that are eligible for the } \\
\text { funding, but have not received it }\end{array}$ & 29 & 2 & -1 & -4 \\
\hline 30 & I have children who are not eligible for this funding, & 30 & 3 & 4 & 2 \\
\hline
\end{tabular}




\begin{tabular}{|c|c|c|c|c|c|}
\hline & but would benefit from it & & & & \\
\hline 31 & $\begin{array}{l}\text { Funding should only be used on resources/support } \\
\text { inside the setting }\end{array}$ & 31 & 0 & 0 & -2 \\
\hline 32 & The eligibility criteria for this funding need to change & 32 & 0 & 1 & 2 \\
\hline 33 & $\begin{array}{l}\text { It is difficult to decide how to use the funding if the } \\
\text { child has no developmental delay }\end{array}$ & 33 & 0 & 3 & -2 \\
\hline 34 & $\begin{array}{l}\text { My position is influenced by my experience } \\
\text { particularly with one child }\end{array}$ & 34 & -1 & -1 & 0 \\
\hline
\end{tabular}

\section{Table 1}

\begin{tabular}{|c|l|l|l|l|}
\hline Participant & Female/Male & Nursery/Preschool & $\begin{array}{l}\text { Role at } \\
\text { setting (if } \\
\text { stated) }\end{array}$ & $\begin{array}{l}\text { Years } \\
\text { experience (if } \\
\text { stated) }\end{array}$ \\
\hline 4 & Female & Preschool & Not stated & Not stated \\
\hline 7 & Female & Preschool & Manager & 14 years \\
\hline 8 & Female & Preschool & $\begin{array}{l}\text { Owner and } \\
\text { Deputy } \\
\text { Manager }\end{array}$ & 5 years \\
\hline 10 & Female & Preschool & Manager & 23 years \\
\hline 13 & Female & Preschool & Manager & 20 years \\
\hline 14 & Female & Preschool & Manager & 10 years + \\
\hline 15 & Female & Nursery & Not stated & Not stated \\
\hline 19 & Female & Nursery & Not stated & Not stated \\
\hline
\end{tabular}

Table 2

\begin{tabular}{|c|l|l|l|l|}
\hline $\begin{array}{l}\text { Participant } \\
\text { number }\end{array}$ & Female/Male & Nursery/Preschool & $\begin{array}{l}\text { Role at setting } \\
\text { (if stated) }\end{array}$ & $\begin{array}{l}\text { Years' } \\
\text { experience (if } \\
\text { stated) }\end{array}$ \\
\hline 2 & Female & Nursery & Manager & 15 years \\
\hline 3 & Female & Preschool & SENCO & Not stated \\
\hline 5 & Female & Nursery & Manager & 10 years \\
\hline 6 & Female & Nursery & Manager & 20 years \\
\hline 9 & Female & Nursery & Manager & 12 years \\
\hline
\end{tabular}




\begin{tabular}{|l|l|l|l|l|}
\hline 17 & Female & Nursery & $\begin{array}{l}\text { Deputy } \\
\text { Manager }\end{array}$ & 10 years \\
\hline 20 & Female & Nursery & Manager & 11 years \\
\hline
\end{tabular}

Table 3

\begin{tabular}{|c|l|l|l|l|}
\hline $\begin{array}{l}\text { Participant } \\
\text { number }\end{array}$ & Female/Male & Nursery/Preschool & $\begin{array}{l}\text { Role at setting } \\
\text { (if stated) }\end{array}$ & $\begin{array}{l}\text { Years' } \\
\text { experience (if } \\
\text { stated) }\end{array}$ \\
\hline 11 & Female & Preschool & Manager & 15 years \\
\hline 12 & Female & Nursery & Not stated & Not stated \\
\hline 16 & Female & Nursery & Owner/manager & 12 years \\
\hline 18 & Female & Nursery & Manager & Not stated \\
\hline
\end{tabular}

Table 4

\begin{tabular}{|l|l|l|l|}
\hline Statement & Factor one & Factor two & Factor three \\
\hline 5. All LAC need this funding & -3 & 1 & -2 \\
\hline $\begin{array}{l}\text { 14. All children from low income families } \\
\text { need this funding }\end{array}$ & -4 & 1 & 1 \\
\hline $\begin{array}{l}\text { 21. This funding 'closes the gap' for LAC } \\
\text { 22. This funding 'closes the gap' for } \\
\text { children from low income families }\end{array}$ & -3 & -1 & 1 \\
\hline
\end{tabular}

\section{Table 5}

\begin{tabular}{|l|l|l|l|}
\hline Application statements & Factor one & Factor two & Factor three \\
\hline $\begin{array}{l}\text { 7. We get the funding too late in the academic } \\
\text { year }\end{array}$ & 4 & 0 & 4 \\
\hline 9. It is easy to access this funding & -4 & -4 & 0 \\
\hline $\begin{array}{l}\text { 27. It is a struggle to get parents to complete } \\
\text { the online form }\end{array}$ & 4 & 3 & 3 \\
\hline 28. I would prefer to apply for funding on & 3 & 4 & 4 \\
\hline
\end{tabular}




\begin{tabular}{|l|l|l|l|}
\hline behalf of children in my care & & & \\
\hline Eligibility statements & & & \\
\hline $\begin{array}{l}\text { 4. The funding would be better used if I could } \\
\text { allocate it to children whom I feel really need } \\
\text { it }\end{array}$ & 3 & 3 & -1 \\
\hline $\begin{array}{l}\text { 16. Children with Special Educational Needs } \\
\text { and Disabilities should be entitled to this } \\
\text { funding }\end{array}$ & 2 & 2 & 2 \\
\hline
\end{tabular}

